\title{
Türk Lirası Referans Faiz Oranı'nı (TRLIBOR) Etkileyen Makroekonomik Faktörlerin Analizi
}

\author{
Murat Akkaya \\ İstanbul Arel Üniversitesi, İBF, Uluslararası Ticaret Finans Bölümü, \\ muratakkaya@arel.edu.tr
}

\begin{abstract}
$\ddot{O ̈ z}$
Faiz oranlarının ekonomide önemli bir rolü bulunmaktadır. Faiz oranlarındaki değişimler ekonomiyi ve finansal piyasaları olumlu ve/veya olumsuz etkileyebilmektedir. Ayrıca faiz oranları fon kanallarını etkilemektedir. TRLIBOR, Türk Lirası Bankalararası Teklif Oranı olarak belirlenen referans faiz oranının kısaltmasıdır ve LIBOR'a eşdeğerdir. Bu çalışmanın amacı Türk Lirası Referans Faiz Oranı'nı etkileyen makroekonomik faktörlerin belirlenmesidir. Bu çalışmada yedi değişken, 2003:01- 2017:06 dönemi ve ARDL Modeli (Otoregresif Dağııık Gecikme Testi) kullanılmıştır. Reel Efektif Döviz Kuru ve Tüketici Fiyatları Endeksi kısa ve uzun vadede anlamlı bulunmuş̧ur. Modeldeki değişkenler arasında eşbütünleşme bulunmaktadır. Eşbütünleşme katsayısına göre, bir dönemin sonunda kısa ve uzun dönemli dengesizlikler yaklaşık \% 18 oranında düzeltilecektir. Ayrıca, Reel Efektif Döviz Kuru ve Tüketici Fiyatları Endeksi kısa vadede $\% 1$ seviyesinde istatiksel anlamlıdır.
\end{abstract}

Anahtar Kavramlar: Faiz Oranları, TRLIBOR, ARDL Model, Reel Efektif Döviz Kuru, Tüketici Fiyatları Endeksi.

JEL Sinıflandırma Kodları: E43, C59, F31, E31.

\section{Macroeconomic Factors Influencing Turkish Lira Reference Interest Rate (TRLIBOR) *}

\begin{abstract}
Interest rates have an important function in an economy. Changes in interest rate can affect both positively and negatively an economy and financial markets. Interest rates also affect the fund channels. TRLIBOR is the abbreviation of the reference interest rate determined as the Turkish Lira Interbank Offer Rate and TRLIBOR is the equivalent of LIBOR. The aim of this study is to determine macroeconomic factors affecting interest rate. This study covers seven variables and the period between 2003:M01 and 2017:M06. ARDL Model indicates the evidence of cointegration between variables. Real Effective Exchange Rate and Consumption Price Index are significant in the short and long term. The variables in the model are cointegration. According to the cointegration coefficient, short and long term imbalances will be corrected by approximately $18 \%$ at the end of a period. In addition, the Real Effective Exchange Rate and Consumer Price Index is statistically significant at $1 \%$ in the short term.
\end{abstract}

Keywords: Interest Rates, TRLIBOR, ARDL Model, Real Effective Exchange Rate and Consumption Price Index.

JEL Classification Codes: E43, C59, F31, E31.

\footnotetext{
"Extended abstract is presented at the end of the article.
}

Attfta bulunmak için/Cite this paper:

Akkaya, M. (2018). Türk Lirası Referans Faiz Oranı'nı (TRLIBOR) etkileyen makroekonomik faktörlerin analizi. Çankırı Karatekin Üniversitesi İ̈BF Dergisi. 8 (2), 179-197. 


\section{Giriş}

Yatırımcılar açısından önemli konulardan biri olan faiz oranı, gelişmiş ve gelişmekte olan ülkelerde çok tartışılan bir konudur. Hangi değişkenlerin faiz oranlarını etkilediği konusu araştırmacıların dikkatini çekmektedir. Çünkü, faiz oranları bir ekonomideki fon kanallarını etkilemektedir.

Referans faiz oranı hareketli bir endekstir, başka bir ifade ile LIBOR'dur. LIBOR (London Interbank Offered Rate), bankalararası piyasada kısa vadeli borçlanmada kullanılan günlük referans oranıdır. Finansal piyasalarda LIBOR oranları önemlidir. LIBOR'un iki ana işlevi vardır: referans oranı ve karşılaştırma oranı olmasi.

TRLIBOR, Türk Lirası Bankalararası Referans Oranı olarak belirlenen referans faiz oranının kısaltmasıdır. TRLIBOR, Türkiye'de bankalar arasında veya bankalar ile müşteriler arasında yapılan işlemlerde esas alınabilecek bir referans faiz oranıdır ve LIBOR'a eşdeğerdir. 2002 yılından bu yana 8 ayrı vadede -günlük, haftalık, aylık, 2 aylık, 3 aylık, 6 aylık, 9 aylık ve 12 aylık dönemler itibarıylailan edilmektedir. TRLIBOR borç verme faiz oranıdır. Borçlanma faiz oranı ise TRLIBID'dir. Türkiye Bankalar Birliği tarafından günlük olarak ilan edilen TRLIBOR ve TRLIBID, gerekli tüm kriterleri karşılayan bankaların katılımı ile hesaplanmaktadir (http://www.trlibor.org).

TRLIBOR, mesai günlerinde saat 11:15'de veri sağlayıcı kurumların TRLIBOR sayfalarında Türkiye Bankalar Birliği tarafından yayınlanmaktadır. Bankalar arasında TRLIBOR; 10:30-11:15 saatleri arasında yapılan işlemlerden 10:4511:15 saatleri arasında girilen kotasyonların 5 defa tesadüfi olarak alınması, her vadede en yüksek ve en düşük üç kotasyon çıkartılması, kalan kotasyonların satış tarafinın aritmetik ortalaması alınması ile tespit edilmektedir. Katılımcı bankalar, 1 Temmuz - 30 Haziran dönemini kapsayan 1 mali yıl için seçilmektedir. Türkiye Bankalar Birliği günlük olarak piyasa derinliği rakamlarını açıklamaktadır.

TRLIBOR ile amaç uzun vadeli Türk Lirası faiz oranları için gösterge (benchmark) oranlar oluşturmaktır. TRLIBOR ile yerli ve yabancı yatırımcılar, Türk Lirası araçlara daha güvenle ve düşük bir karşılık ayırarak yatırım yapabilmektedir. TRLIBOR, non-interbank diye bilinen piyasada bankaların kendi arasında işlem yaptıklarında kullandıkları orandır. T.C. Merkez Bankası bünyesinde faaliyet gösteren Bankalararası Para Piyasası (Interbank) işlemlerinde kullanılan gecelik veya vadeli faiz oranı ise T.C. Merkez Bankasının belirli vadeler ile bankalara teminat ve limitleri doğrultusunda sağladığı mevduatlara uyguladığı faiz oranıdır. Bankalar bu sayede T.C. Merkez Bankasının gün içerisinde ilan ettiği faiz oranlarından Türk lirası borç alıp verebilmektedir. 
Türk Liras1 Bankalararası Referans Oran1, 2003:01-2017:06 döneminde \% 46.0'dan \% 12.38'e düşmüştür (Şekil 1).

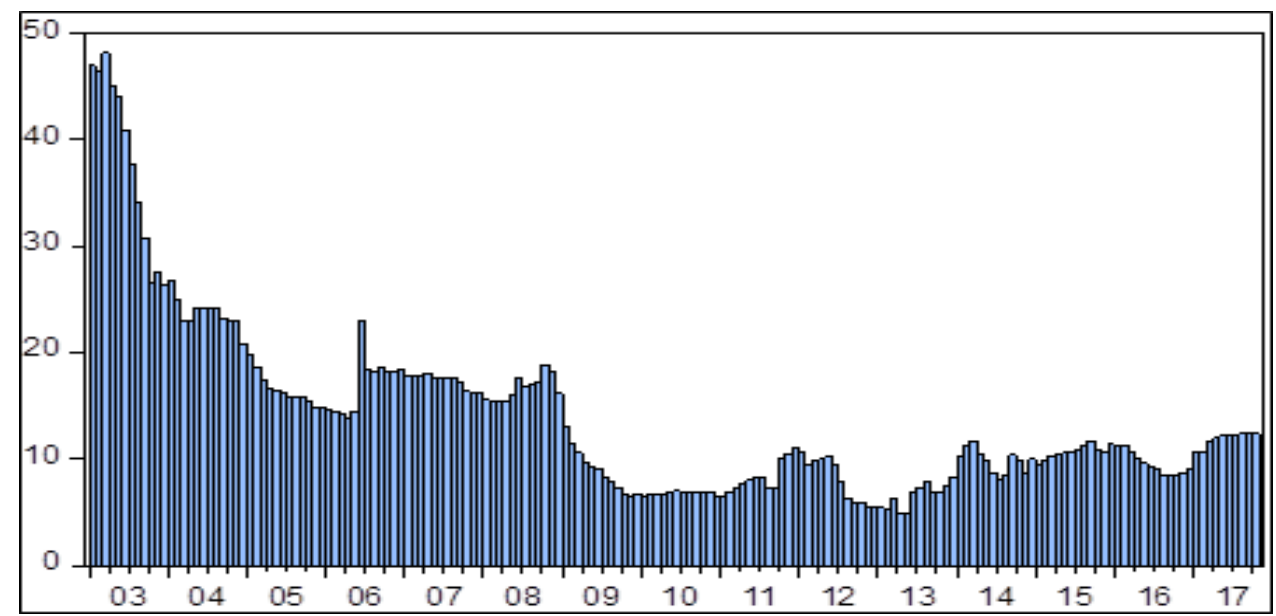

Şekil 1: TRLIBOR (Aylık)

Kaynak: yazar tarafindan oluşturulmuştur

Faiz oranı ile ilgili birçok çalışma bulunmaktadır. Bu çalışmalarda faiz oranları ile enflasyon, hisse senedi fiyatları, döviz kuru, borç stoğu arasındaki ilișki ele alınmaktadır. Türk Lirası Referans Faiz Oranı (TRLIBOR) ile makroekonomik faktörler arasındaki ilişkiyi araştıran çok az çalışma bulunmaktadır. Bu çalışmanın amacı, makroekonomik faktörler ile faiz oranı arasındaki ilişkiyi belirlemektir.

\section{Literatür}

Literatürdeki çalışmalar genellikle Fisher denklemine dayanmaktadır. Faiz oranı ile diğer değişkenler arasındaki ilişki üzerine çalışmalar özeti Tablo 1'de verilmektedir.

Literatür incelemesi iki kısma ayrılmıştır. İlk bölüm, enflasyon ile faiz oranı arasındaki ilişkiyi inceleyen çalışmaları kapsamaktadır. Literatürde tartışılan konulardan biri hangisinin birbirini etkilediğidir. Lee (1992), ABD'de 1947-1987 dönemi için 492 aylık verilerden oluşan örneklemi Granger Nedensellik Testi ile analiz ederek faiz, enflasyon ve hisse senedi getirisi arasındaki nedensel ilişkisini araştırmış ve faiz oranlarının enflasyon üzerine büyük bir açıklama gücünün bulunduğunu görmüştür. Asari ve diğerleri (2011) ve Amaefula (2016), Lee'nin yöntemini kullanarak benzer sonuçları gözlemlemiş ve faiz oranından enflasyona doğru tek yönlü nedensellik ilişsisi bulunmuştur. 
Tablo 1: Literatür Özeti

\begin{tabular}{|c|c|c|c|}
\hline Yazar & Metod & Yer & Sonuçlar \\
\hline $\begin{array}{l}\text { Hashemzadeh \& } \\
\text { Taylor (1988) }\end{array}$ & Granger-Sims Causality & USA & $\begin{array}{l}\text { Faiz oranlarından hisse senedi fiyatlarına } \\
\text { çok düşük nedensellik ilişkisi. }\end{array}$ \\
\hline $\begin{array}{l}\text { Edison and Pauls } \\
\text { (1993) }\end{array}$ & $\begin{array}{l}\text { Engle-Granger } \\
\text { Eşbütünleşme }\end{array}$ & $\begin{array}{l}\text { G-10 } \\
\text { Ülkeleri }\end{array}$ & $\begin{array}{l}\text { Reel döviz kuru ile faiz oranı arasında bir } \\
\text { ilişki yok. }\end{array}$ \\
\hline $\begin{array}{l}\text { Berument and } \\
\text { Malatyal1 }(2001)\end{array}$ & GARCH & Turkey & $\begin{array}{l}\text { Enflasyon riski, faiz oranlarının artmasına } \\
\text { neden olmaktadır. }\end{array}$ \\
\hline $\begin{array}{l}\text { Booth and Ciner } \\
(2001)\end{array}$ & Johansen Cointegration & $\begin{array}{l}\text { G-10 } \\
\text { Ülkeleri }\end{array}$ & $\begin{array}{l}\text { Faiz oranları ile beklenen enflasyon } \\
\text { arasındaki yakın ilişki. }\end{array}$ \\
\hline Karaca (2005) & ARDL & Türkiye & $\begin{array}{l}\text { Döviz kuru ile faiz oranı arasında anlamlı } \\
\text { bir ilişki yok. }\end{array}$ \\
\hline $\begin{array}{l}\text { Sever and Mizrak } \\
(2007)\end{array}$ & VAR & Türkiye & $\begin{array}{l}\text { Döviz kurundaki bir değişikliğin faiz } \\
\text { üzerinde etkisi vardır. }\end{array}$ \\
\hline Laubach (2007) & Regresyon & USA & $\begin{array}{l}\text { Devlet borçları ve bütçe açılkları faiz } \\
\text { oranlarında istatiksel olarak önemlidir. }\end{array}$ \\
\hline $\begin{array}{l}\text { Asari et. al. } \\
(2011)\end{array}$ & $\begin{array}{l}\text { VECM, Granger } \\
\text { Causality }\end{array}$ & Malezya & $\begin{array}{l}\text { Faiz oranı ile enflasyon arasındaki tek } \\
\text { yönlü nedensellik ilişkisi. }\end{array}$ \\
\hline Mercan (2013) & Johansen Cointegration & Türkiye & $\begin{array}{l}\text { Enflasyon oran } 1 \text { nominal faiz oranın } 1 \\
\text { olumlu etkiliyor. }\end{array}$ \\
\hline $\begin{array}{l}\text { Turan and Curri } \\
\text { (2014) }\end{array}$ & Johansen Cointegration & Arnavutluk & $\begin{array}{l}\text { Enflasyon ve faiz oranları arasında uzun } \\
\text { vadeli bir ilişki bulunmuştur. }\end{array}$ \\
\hline $\begin{array}{l}\text { Tanriöver and } \\
\text { Yamak (2015) }\end{array}$ & ARDL & Türkiye & Enflasyon ile nominal faiz arasındaki ilişki. \\
\hline $\begin{array}{l}\text { Doğan et. al. } \\
\text { (2016) }\end{array}$ & $\begin{array}{l}\text { Johansen Cointegration, } \\
\text { Granger Causality }\end{array}$ & Türkiye & $\begin{array}{l}\text { Enflasyon } \\
\text { nedensellik }\end{array} \quad$ oranından faiz oranına \\
\hline $\begin{array}{l}\text { Cologni and } \\
\text { Manera (2016) }\end{array}$ & VAR & G-7 Ülkeleri & $\begin{array}{l}\text { Petrol fiyat şoklarında beklenmeyen bir } \\
\text { şok, faiz oranlarının etkilenmesine neden } \\
\text { olur. }\end{array}$ \\
\hline
\end{tabular}

Kaynak: yazar tarafindan oluşturulmuştu

Berument ve Malatyalı (2001), Türkiye için GARCH modelini kullanarak 19891998 dönemi aylık verilerini analiz etmişler ve enflasyon dönemlerinde faiz oranlarının arttığını gözlemlemişlerdir. Bu çalışmaya ek olarak Mercan (2013), Tanriöver ve Yamak (2015) ve Doğan ve diğerleri (2016), Türkiye'de enflasyon oranı ile faiz oranı arasında istatistiksel olarak anlamlı ve pozitif bir ilişki olduğunu kanıtlamıştır. Bohça ve Ciner (2001) ve Turan ve Curri (2014), Johansen Eşbütünleşme Testi kullanarak enflasyon ve faiz oranları arasında uzun 
dönemli bir ilişki olduğunu ortaya koymuşlardır. Öte yandan, Mehdi ve Masood (2011) ise uzun vadede aralarında zayıf bir ilişki olduğunu iddia etmektedir.

İkinci bölümünde ise, enflasyon hariç diğer değişkenlere ait çalışmalar yer almaktadır. Hashemzadeh ve Taylor (1988), ABD'de hisse senedi fiyatları ve faiz oranı arasındaki ilişkiyi araştırmış ve hisse senedi fiyatları ile faiz oranı arasında çok düşük bir ilişki olduğunu belirtmişlerdir. Apergis ve Eleftheriou (2002), hisse senedi fiyatlarının enflasyon üzerinde faiz oranından daha fazla etkili olduğu savunarak Hashemzadeh ve Taylor'un çalışmasını desteklemektedir. Mok (1993), Hong Kong'daki faiz oranları ile hisse senedi fiyatları arasında istatistiksel olarak anlamlı bir ilişki bulunduğunu söylemektedir.

Ayrıca, Edison ve Pauls (1993), G-10 Ülkelerinin 66 üç aylık veri setlerini EngleGranger Eşbütünleşme Testi ile analiz ederek reel döviz kurunun faiz oranı üzerindeki etkilerini incelemiş ve reel döviz kuru ile faiz oranı arasında bir ilişki olmadığını gözlemlemiştir. Karaca (2005) da aynı sonuca ulaşmıştır. Sever ve Mızrak (2007) ise faiz oranlarının reel döviz kurundaki değişime tepki verdiğini belirtmektedir.

Kalulumia (2002), ABD, İngiltere, Almanya ve Kanada'da devlet borç stoku ile faiz oranı arasında bir ilişkiyi incelemiş ve aralarında ilişki bulunmadığını gözlemlemiştir. Laubach (2007) ise hükümet borçlarının ve bütçe açıklarının faiz oranlarını istatistiksel olarak etkilediği sonucuna varmıştır. Ayrıca, Wang ve Chueh (2013), faiz oranının gelecekteki altın fiyatlarını olumsuz etkilediğini ve gelecekteki ham petrol fiyatlarını ise olumlu etkilediğini belirtmektedir. Cologni ve Manera'ya (2016) göre petrol fiyat şokları faiz oranlarını etkilemektedir.

\section{Veri ve Yöntem}

\subsection{Veri ve Değişkenler}

Bu çalışmada 2003:01 ve 2017:06 y1lı arasındaki dönemi kapsayan yedi değişken ve 174 aylık gözlem bulunmaktadır. Çalışmanın amacı TRLIBOR oranı ile makroekonomik faktörler arasındaki ilişkinin belirlenmesidir. Veriler Türkiye İstatistik Kurumu (TÜİK) ve Türkiye Bankalar Birliği web sitelerinden elde edilmiş ve değişkenler Tablo 2'de sunulmuştur. 
Tablo 2: Değişkenler

\begin{tabular}{lll}
\hline \multicolumn{1}{c}{ Değişkenler } & \multicolumn{1}{c}{$\begin{array}{c}\text { Literatürdeki } \\
\text { Değişkenler }\end{array}$} & \multicolumn{1}{c}{ Referanslar } \\
\hline Tüketici Fiyatları Endeksi & Enflasyon Oranı & $\begin{array}{l}\text { Lee (1992), Berument ve Malatyalı (2001), Booth } \\
\text { ve Ciner (2001), Asari et. al. (2011), Mahdi ve } \\
\text { Masood (2011), Mercan (2013), Turan ve Curri } \\
\text { (2014), Tanrı̈̈ver ve Yamak (2015), Doğan et. al. }\end{array}$ \\
\hline BIST100 Endeksi & Hisse senedi & $\begin{array}{l}\text { Hashemzadeh ve Taylor (1988), Mok (1993), } \\
\text { Asari et. al. (2011) }\end{array}$ \\
\hline Reel Efektif Döviz Kuru & Fiyatları & $\begin{array}{l}\text { Edison ve Pauls (1993), Karaca (2005), Sever ve } \\
\text { Mizrak (2007) }\end{array}$ \\
\hline Ham Petrol Fiyatı (varil) (\$) & Petrol Fiyatı & $\begin{array}{l}\text { Wang ve Chueh (2013), Cologni ve Manera } \\
\text { (2016) }\end{array}$ \\
\hline Yurtiçi Borç Stoku (TL) & Kamu Borçları & Kalulumia (2002), Laubach (2007) \\
\hline Altın Fiyatı (Gram) (TL) & Altın Fiyatı & Wang ve Chueh (2013) \\
\hline Bütçe Dengesi (TL) & Bütçe Açıkları & \begin{tabular}{l} 
Laubach (2007) \\
\hline
\end{tabular} \\
\hline
\end{tabular}

\subsection{Otoregresif Dağıtık Gecikme (ARDL) Modeli}

Engle ve Granger (1987), Johansen (1988) ve Johansen ve Juselius (1990) Eşbütünleşme Testleri genellikle eşbütünleşmeyi test etmek ve değişkenler arasındaki uzun dönemli ilişkiyi incelemek için kullanılmaktadır. Bu testler tüm serilerin birim köke sahip olması ve birinci fark seviyede durağan olması durumunda uygulanabilmektedir. Serinin farklı durağanlık seviyeleri varsa, bu testlerin uygulanması mümkün değildir. Bununla birlikte, Pesaran ve Pesaran (1997), Pesaran ve Shin (1998) ve Pesaran ve diğerleri (1998) tarafindan geliştirilen Otoregresif Dağıtık Gecikme (ARDL) (Otoregressive Distributed LagARDL) yaklaşımı, (2001) bu önkoşulları geçersiz kılmaktadır. ARDL test yaklaşımında modelin değişkenlerinin orijinal seviyede ya da ilk fark seviyesinde durağan olup olmadığı önemli değildir. Bu testin avantajı farklı durağanlık seviyesinde olan değişkenler arasında eşbütünleşme analizine izin vermesidir.

ARDL yaklaşımı 3 adımlı bir süreçten oluşmaktadır. İlk adımda ARDL Sınır Testi değişkenler arasındaki uzun dönemli ilişkinin varlığını incelemektedir. İkinci ve üçüncü adımlar koşullu olarak değişkenler arasında uzun dönemli bir ilişkiyi incelemektedir. Dolayısıyla sirasiyla uzun vadeli ve k1sa vadeli katsayılara ulaş1labilmektedir (Narayan ve Smyth, 2006, sayfa 337). 


\section{Bulgular}

\subsection{Birim Kök Testi}

Zaman serilerinin analizinde durağanlık testi gerekmektedir. Phillips ve Perron (1988) testi zaman serilerinin durağanlık sırasını incelemede en popüler yöntemlerden biridir ve bu çalışmada tercih edilmiştir. Augemented Dickey-Fuller (ADF) birim kök testi hata terimlerinin istatistiki olarak bağımsız olduklarını ve sabit varyansa sahip olduklarını varsayar. Phillips-Perron (PP) birim kök testi ise hata teriminin zayıf derecede bağımlı olmasına ve heterojen olarak dağılmasına izin vermektedir. Bu sayede otokorelasyon sorunu ortaya çıkmamaktadır. Phillips ve Perron (1988), Dickey-Fuller'nn hata terimleri ile ilgili varsayımın genişletmişlerdir.

Phillips-Perron (PP) Birim Kök Testi'ni kullanarak 8 değişkenin durağan olup olmadığ 1 ve/veya seviyede ve ilk fark düzeyinde durağanlığ 1 kontrol edilmiş ve Phillips-Perron (PP) Test sonuçları Tablo 3 'te verilmiştir.

Tablo 3: Phillips-Perron Birim Kök Test

\begin{tabular}{lcccc}
\hline \multirow{2}{*}{ Değişkenler } & \multicolumn{2}{c}{ Düzey } & 1. & Fark \\
\cline { 2 - 4 } & t-Statistic & P Değeri & t-Statistic & P Değeri \\
\hline Tüketici Fiyatları Endeksi & 1.958487 & 1.0000 & -11.76292 & 0.0000 \\
\hline İç Borç stoku & -1.906502 & 0.6469 & -10.19894 & 0.0000 \\
\hline Altın Fiyatı & -2.107018 & 0.5379 & -11.56593 & 0.0000 \\
\hline Ham Petrol Fiyatı & -2.803421 & 0.1981 & -9.796529 & 0.0000 \\
\hline BIST100 Endeksi & -3.072747 & 0.1162 & -12.80797 & 0.0000 \\
\hline Reel Efektif Döviz Kuru & -3.236680 & 0.0808 & -9.910657 & 0.0000 \\
\hline Bütçe Dengesi & -19.12797 & 0.0000 & & \\
\hline TRLIBOR & -5.135025 & 0.0000 & & \\
\hline
\end{tabular}

a. Trend ve Kesişim dahil.

PP Birim Kök Test sonuçları; Türk Lirası Referans Faiz Oranı ve Bütçe Dengesi'nin düzey seviyede, Tüketici Fiyat Endeksi, İç Borç Stoku, Altın Fiyatı, Ham Petrol Fiyat1, BİST 100 Endeksi ve Reel Efektif Döviz Kuru'nun ise 1. fark seviyede durağan olduğunu göstermektedir Değişkenler farklı durağanlık derecelerine sahip olduklarından tüm değişkenlerin endojen olduğunu varsayan ARDL testi ile devam edilecektir. 
Ayrıca, Dickey ve Fuller (1981) tarafından geliştirilen, Augmented Dickey-Fuller (ADF) birim kök testi uygulanmıştır. \% 1 anlamlılık düzeyinde TRLIBOR hariç diğer değişkenlerin düzey seviyede durağan olmadığı, 1. farklarda birim kök taşımadığı, yani durağan olduğu görülmüştür (Tablo 4).

Tablo 4: Augmented Dickey-Fuller (ADF) birim kök testi

\begin{tabular}{|l|r|l|r|}
\hline Değişkenler & \multicolumn{1}{|c|}{ Prob. ${ }^{*}$} & & \multicolumn{1}{c|}{ Prob. ${ }^{*}$} \\
\hline BIST 100 & 0.7955 & 1. fark & 0.0000 \\
\hline COIL & 0.2355 & 1. fark & 0.0000 \\
\hline GBD & 0.1409 & 1. fark & 0.0000 \\
\hline GOLD & 0.9963 & 1. fark & 0.0000 \\
\hline IBS & 0.9395 & 1. fark & 0.0000 \\
\hline REER & 0.1275 & 1. fark & 0.0000 \\
\hline TRLIBOR & 0.0000 & & \\
\hline TUFE & 1.0000 & 1. fark & 0.0000 \\
\hline
\end{tabular}

\subsection{ARDL Test Sonuçları}

Çalışmada kullanılan verilerin büyük bir çoğunluğu 1. fark seviyesinde durağandır. Yalnızca TRLIBOR ve Bütçe Dengesi değişkenleri düzey seviyede durağandır. $\mathrm{Bu}$ durum, eşbütünleşme ilişkisini incelemek için ARDL Modelinin uygulanabileceğini göstermektedir. ARDL modelini uygulamak için öncelikle optimal gecikme uzunluğu belirlenmelidir.

Tablo 5: Gecikme Uzunluğu Testi

\begin{tabular}{ccccccc}
\hline Gecikme & LogL & LR & FPE & AIC & SC & HQ \\
\hline 0 & -9646.418 & NA & $1.14 \mathrm{e}+40$ & 114.9336 & 115.0823 & 114.9939 \\
\hline 1 & -7913.401 & 3280.354 & $2.67 \mathrm{e}+31$ & 95.06430 & $96.40314^{*}$ & $95.60767^{*}$ \\
\hline 2 & -7840.232 & 131.5300 & $2.41 \mathrm{e}+31$ & 94.95515 & 97.48407 & 95.98151 \\
\hline $\mathbf{3}$ & -7766.193 & 126.0430 & $\mathbf{2 . 1 6 e + 3 1 *}$ & $\mathbf{9 4 . 8 3 5 6 3 *}$ & 98.55464 & 96.34498 \\
\hline 4 & -7724.678 & 66.71998 & $2.89 \mathrm{e}+31$ & 95.10331 & 100.0124 & 97.09566 \\
\hline 5 & -7665.202 & $89.92234 *$ & $3.17 \mathrm{e}+31$ & 95.15717 & 101.2563 & 97.63251 \\
\hline 6 & -7615.194 & 70.84539 & $3.98 \mathrm{e}+31$ & 95.32373 & 102.6130 & 98.28207 \\
\hline a. & “*” seçilen gecikme uzunluğu kriteri & & & & \\
\hline
\end{tabular}


FPE (Son Tahmin hatasi), AIC (Akaike Bilgi Kriteri), SC (Schwarz Bilgi Kriteri) ve HQ (Hannan-Quinn Bilgi Kriteri) Bilgi Ktriterleri optimum gecikme uzunluğunu belirlemek için kullanılan kritik değerlerdir. En düşük kritik değeri sağlayan gecikme uzunluğu, modelin optimum gecikme süresi olarak belirlenir. Bununla birlikte, modelin belirtilen gecikme uzunluğunda bir otokorelasyon problemi varsa sonraki minimum kritik değeri sağlayan gecikme süresinde bir otokorelasyon sorununun olup olmadiğ 1 kontrol edilmektedir. Lagrange Çarpanı (LM) Testi modelde otokorelasyon varlı̆̆ını incelemektedir.

Tablo 6: Otokorelasyon LM Test

\begin{tabular}{ccc}
\hline Gecikme & LM Statistic Value & P Value \\
\hline $\mathbf{1}$ & 126.5789 & 0.0000 \\
\hline $\mathbf{2}$ & 125.9212 & 0.0000 \\
\hline $\mathbf{3}$ & 75.24237 & 0.1589 \\
\hline
\end{tabular}

En küçük SC ve HQ değerleri ilk gecikme, en küçük FPE ve AIC değerleri Tablo 5 'teki üçüncü gecikme değeridir. Ancak, Tablo 5 ve Tablo 6 birlikte incelendiğinde, en uygun gecikme uzunluğunun 3 olduğu görülmektedir. İlk gecikme otokorelasyon probleminden kaynaklanmaktadır. Tablo 6, olasılık değerinin, üçüncü gecikmede 0.05 'den büyük olduğunu ortaya koymaktadır. FPE ve AIC, en düşük ilk kritik değerini üçüncü aşamada almaktadır. Bu nedenle, üçüncü gecikme döneminde otokorelasyon olmadığı açıktır. Otokorelasyonun yanı sıra White Test ile değişen varyans varlığı araştırılmış ve modelde seğişen varyans bulunmamaktadir.

Tablo 7'deki sonuçlar, modeldeki değişkenler arasındaki eşbütünleşme kanıtını göstermektedir.

$\mathrm{R}^{2}$ ve Düzeltilmiş $\mathrm{R}^{2}$ değerleri çok yüksektir ve model istatistiksel olarak anlamlıdır. Brown ve diğerleri (1975) tarafindan geliştirilen CUSUM Testi modelde yapısal bir kırılma olup olmadığını test etmek için uygulanmıştır. CUSUM Testi, " $\mathrm{n}$ " gözlem sayısıyla ilişkili birikimli hata terimlerine dayanır ve \% 5 anlamlılık ile iki kritik çizgi arasında çizilmektedir. Eğri iki kritik sınır arasında bulunuyorsa, tahmin edilen katsayılar uzun vadede durağandır. Ayrıca, CUSUM SQ Testi modeldeki daha ayrıntılı yapısal kırılmaları göstermektedir. CUSUM ve CUSUM SQ Testi sonuçları Şekil 2'de sunulmuştur. 
Tablo 7: ARDL (3, 2, 1, 0, 1, 0, 0, 3) Model Tahmin Sonuçları

\begin{tabular}{|c|c|c|c|c|c|}
\hline Variables & \multicolumn{2}{|c|}{ Kats ayı } & Std. Hata & t-Statistic & P Değeri \\
\hline TRLIBOR [-1] & \multicolumn{2}{|c|}{0.730863} & 0.075256 & 9.711 .700 & 0.0000 \\
\hline TRLIBOR [-2] & \multicolumn{2}{|c|}{0.179361} & 0.091247 & 1.965 .658 & 0.0512 \\
\hline TRLIBOR [-3] & \multicolumn{2}{|c|}{-0.100639} & 0.064424 & -1.562 .138 & 0.1203 \\
\hline BIST100 Endeksi & \multicolumn{2}{|c|}{$-4.09 E-05$} & 2.15E-05 & -1.902 .294 & 0.0590 \\
\hline BIST100 Endeksi [-1] & \multicolumn{2}{|c|}{ 3.90E-05 } & 2.83E-05 & 1.379 .258 & 0.1698 \\
\hline BIST100 Endeksi [-2] & \multicolumn{2}{|c|}{ 4.27E-05 } & 2.30E-05 & 1.854 .331 & 0.0656 \\
\hline Reel Efektif Döviz Kuru & \multicolumn{2}{|c|}{-0.145283} & 0.031025 & -4.682 .771 & 0.0000 \\
\hline Reel Efektif Döviz Kuru [-1] & \multicolumn{2}{|c|}{0.062682} & 0.035146 & 1.783 .478 & 0.0765 \\
\hline Bütçe Dengesi & \multicolumn{2}{|c|}{$1.61 \mathrm{E}-05$} & 1.54E-05 & 1.045 .321 & 0.2975 \\
\hline Altın Fiyatı & \multicolumn{2}{|c|}{-0.054208} & 0.028877 & -1.877 .237 & 0.0624 \\
\hline Altın Fiyatı [-1] & 0.05 & 7894 & 0.028707 & 2.016 .696 & 0.0455 \\
\hline Ham Petrol Fiyatı & 0.00 & 1606 & 0.002948 & 0.544694 & 0.5868 \\
\hline İç Borç stoku & -4.36 & E-08 & $1.25 \mathrm{E}-08$ & -3.479 .302 & 0.0007 \\
\hline Tüketici Fiyatları Endeksi & 0.13 & 2870 & 0.053688 & 2.474 .873 & 0.0144 \\
\hline Tüketici Fiyatları Endeksi [-1] & -0.04 & 2606 & 0.082626 & -0.515650 & 0.6068 \\
\hline Tüketici Fiyatları Endeksi [-2] & 0.04 & 5094 & 0.092025 & 0.490014 & 0.6248 \\
\hline Tüketici Fiyatları Endeksi [-3] & -0.10 & 8931 & 0.063394 & -1.718 .326 & 0.0878 \\
\hline Kukla Değişken & 0.76 & 0491 & 0.364230 & 2.087 .940 & 0.0385 \\
\hline Sabit Terim & 1.79 & 1.242 & 3.728 .911 & 4.803 .661 & 0.0000 \\
\hline R-squared & 0.985395 & & & & \\
\hline Adjusted R-squared & 0.983665 & Mear & dent var & & 1.348 .120 \\
\hline S.E. of regression & 0.938184 & S.D.C & ent var & & 7.340 .619 \\
\hline Sum squared resid & 1.337 .889 & Akai & criterion & & 2.814 .699 \\
\hline Log likelihood & -2.216 .568 & Schw & terion & & 3.163.773 \\
\hline F-statistic & 5.697 .386 & Hann & inn criter. & & 2.956 .338 \\
\hline Prob(F-statistic) & 0.000000 & Durb & son stat & & 1.991 .533 \\
\hline Bağımlı Değişken: TRLIBOR & & & & & \\
\hline
\end{tabular}
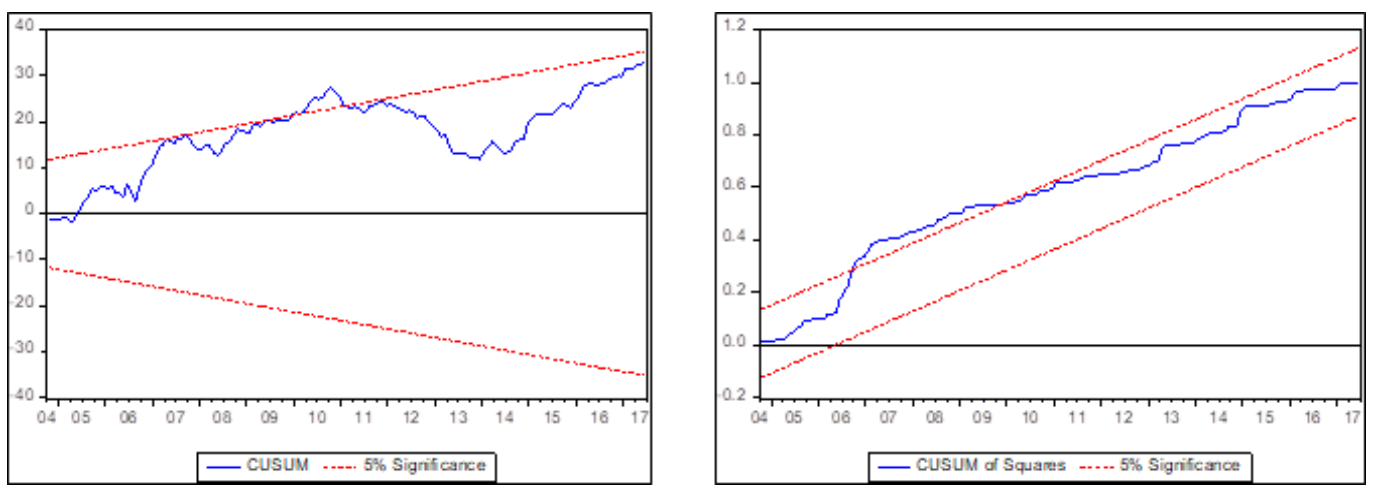

\section{Şekil 2: CUSUM ve CUSUM SQ Test Sonuçları}

Şekil 2 modelde bir yapısal kırılma olduğunu göstermektedir. Küresel kriz döneminde krizin etkileri açıkça görülmektedir. Bu nedenle, 2010:M03-2011:M02 dönemi için kukla değişken eklenmesi gerekmektedir. Modele kukla değişken ekledikten sonra CUSUM ve CUSUM SQ Testlerinin sonuçları Şekil 3'de 
gösterilmiştir. CUSUM ve CUSUM SQ Test sonuçlarına göre kukla değişkenli modelde yapısal kırılma bulunmamaktadır.
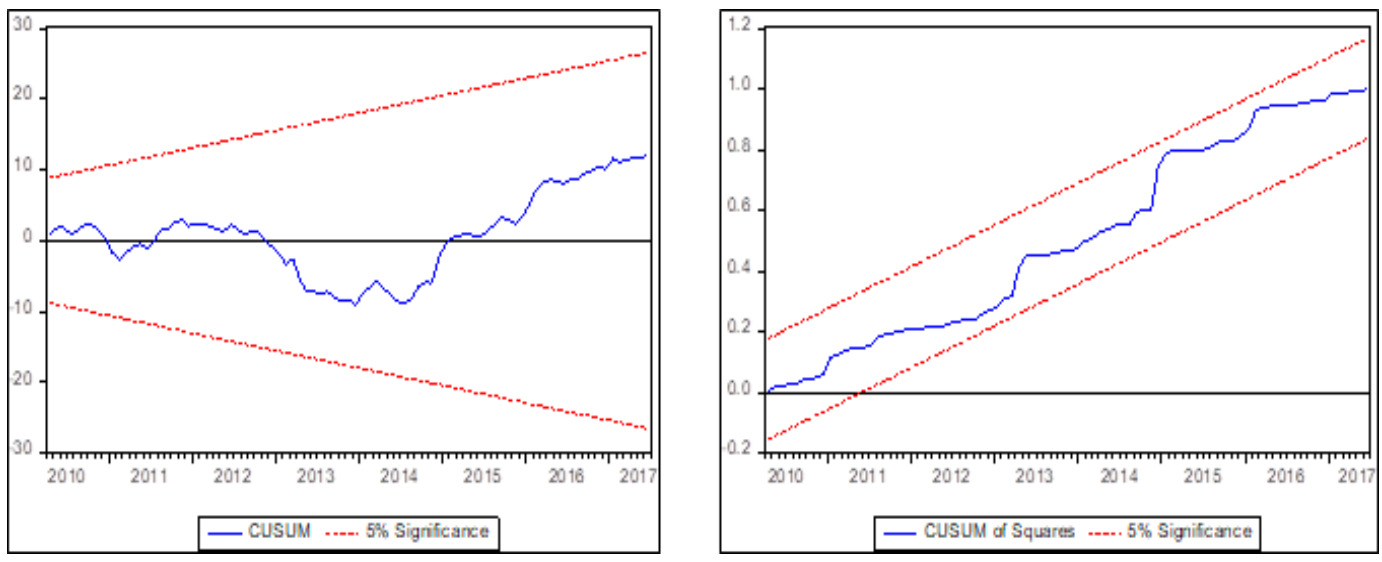

Şekil 3: Kukla Değişkenli CUSUM ve CUSUM SQ Test Sonuçları

Ayrıca modelin varsayım testleri yapılmış ve kukla değişkenli modelin katsayısı \% 5 seviyesinde istatistiksel olarak anlamlı çıkmıştır. Varsayım testlerinin sonuçları modelin uygun olduğunu göstermektedir. Ramsey RESET testine göre model dişı tutulan değişkenler bulunmamaktadır. Diğer testler, modelde otokorelasyon ve değişen varyans probleminin (heteroscedastisite) mevcut olmadı ğını göstermektedir (Tablo 8).

Tablo 8: Varsayım Testleri

\begin{tabular}{lc}
\hline \multicolumn{1}{c}{ Tests } & P Value \\
\hline Ramsey RESET Test & 0.5220 \\
\hline Breusch-Godfrey Serial Correlation LM Test & 0.6688 \\
\hline Heteroscedasticity Test: Harvey & 0.6299 \\
\hline
\end{tabular}

Modelin varsayım testlerinden sonra, seriler arasındaki uzun dönemli bir ilişkinin varlığını ve eşbütünleşme ilişkisini belirlemek için ARDL Sınır Testi uygulanmıştır. F-istatistik değeri Pesaran ve diğerlerinde tablo kritik değerleri ile karşılaştırılmıştır. F değerinin, üst ve alt kritik değerlerin üstünde olması seriler arasında uzun vadeli bir ilişkinin varlığına işaret etmektedir. ARDL Sınır Testi sonuçları Tablo 9'da sunulmuştur. 
Tablo 9: ARDL (3, 2, 1, 0, 1, 0, 0, 3) Sınır Testi Sonuçları

\begin{tabular}{ccccc}
\hline F-statistics & $\mathbf{k}$ & Significance & Alt Sınır & Üst Sınır \\
\hline 6.535066 & 8 & $5 \%$ & 2.11 & 3.15 \\
\hline
\end{tabular}

a. “k” bağımsız değişken sayısını göstermektedir..

Tablo 10: ARDL (3, 2, 1, 0, 1, 0, 0, 3) Model Kısa Dönem Katsayıları

\begin{tabular}{|c|c|c|c|c|}
\hline Değişkenler & Katsayı & Std. Hata & t-Statistic & P Değeri \\
\hline D(TRLIBOR [-1]) & -0.077426 & 0.062990 & -1229173 & 0.2209 \\
\hline D(TRLIBOR [-2]) & 0.104295 & 0.060793 & 1.715 .576 & 0.0883 \\
\hline D(BIST100 Endeksi) & -0.000039 & 0.000020 & -1.913 .601 & 0.0576 \\
\hline D(BIST100 Endeksi [-1]) & -0.000043 & 0.000022 & -1968407 & 0.0508 \\
\hline D(Reel Efektif Döviz Kuru) & -0.143922 & 0.029631 & -4.857 .099 & $0.0000^{*}$ \\
\hline D(Bütçe Dengesi) & 0.000015 & 0.000009 & 1.696 .777 & 0.0918 \\
\hline D(Altın Fiyatı) & -0.054584 & 0.027522 & -1.983 .315 & $0.0491^{* *}$ \\
\hline D(Ham Petrol Fiyatı) & 0.005919 & 0.006701 & 0.883355 & 0.3784 \\
\hline D(İç Borç Stoku) & -0.000000 & 0.000000 & -1.722 .122 & 0.0871 \\
\hline D(Tüketici Fiyatları Endeksi) & 0.132827 & 0.048907 & 2.715 .908 & $0.0074^{*}$ \\
\hline D(Tüketici Fiyatları Endeksi [-1]) & 0.064359 & 0.048337 & 1331476 & 0.1850 \\
\hline D(Tüketici Fiyatları Endeksi [-2]) & 0.108661 & 0.050592 & 2147778 & $0.0333^{* *}$ \\
\hline D(Kukla Değişken) & 0.296698 & 0.657972 & 0.450928 & 0.6527 \\
\hline CointEq[-1] & -0.189112 & 0.024622 & -7.680 .619 & $0.0000^{*}$ \\
\hline \multicolumn{5}{|l|}{ BağımIı Değişken: TRLIBOR } \\
\hline \multicolumn{5}{|c|}{$\begin{array}{l}\text { a. “*” and “***” represent a statistical significance at } 1 \% \text { and } 5 \% \text { leve } \\
\text { respectively. }\end{array}$} \\
\hline \multicolumn{5}{|c|}{ b. The data in square brackets represent the lag length. } \\
\hline
\end{tabular}

F-istatistik değeri, kritik üst sınır değerinden yüksek olduğu için modelde bir eşbütünleşme ilişkisi bulunmaktadır. Bu nedenle ARDL Modeli, uzun ve kısa dönemli katsayıları belirlemek için oluşturulabilir. Bu modelin kısa dönem katsayı sonuçları Tablo 10'da gösterilmiştir. CointEq (-1) eşbütünleşme katsayısını temsil etmektedir. Bu katsayı, uzun dönemli ilişkiden elde edilen hata terimlerinin tek dönemli gecikmeli değeridir ve kısa dönemdeki dengesizliğin ne kadarının uzun vadede düzeltileceğini göstermektedir. Başka bir ifadeyle, hata düzeltme teriminin katsayısı olarak tanımlanabilir. Olumsuz ve istatistiksel olarak anlamlı olması beklenmektedir. Tablo 9'daki hata düzeltme teriminin katsayısı negatiftir ve istatistiksel olarak anlamlıdır $(0.00<0.01)$. Eşbütünleşme katsayısına göre, bir dönemin sonunda kısa ve uzun dönemli dengesizlikler yaklaşık \% 18 oranında 
düzeltilecektir. Ayrıca, Reel Efektif Döviz Kuru ve Tüketici Fiyatları Endeksi kısa vadede \% 1 seviyesinde istatiksel anlamlıdır. Reel Efektif Döviz Kuru'ndaki bir puanlık değişim TRLIBOR'u olumsuz bir şekilde \% 14 oranında etkilemektedir ve Tüketici Fiyatları Endeksi n'de bir puanlık değişim \% 13 oranında TRLIBOR'u olumlu yönde etkilemektedir. Tüketici Fiyatları Endeksi ve Reel Efektif Döviz Kurunun yanı sıra, Altın Fiyatı kısa dönemde TRLIBOR üzerinde bir etkiye sahiptir ve Altın Fiyatındaki bir puanlık artış TRLIBOR'da yaklaşık\% 5 düşüşe neden olmaktadır.

Uzun dönem katsayıları Tablo 11'de verilmektedir. BIST100 Endeksi, İç Borç Stoku, Reel Efektif Döviz Kuru ve Tüketici Fiyatları Endeksi uzun dönemde \% 1 düzeyinde istatistiksel olarak anlamlıdır. İç Borç Stokunun istatistiki olarak anlamlı olmasına rağmen katsayısı neredeyse sıfıra eşittir. Ayrıca, TRLIBOR ile BIST100 Endeksi arasında zayıf bir ilişki bulunmakatdır. Öte yandan, Reel Efektif Döviz Kuru ve Tüketici Fiyatları Endeksi TRLIBOR'u kısa dönmde olduğu gibi uzun dönemde de etkilemektedir. Bu çalışmanın sonuçları, Berument ve Malatyalı (2001), Booth ve Ciner (2001), Sever ve Mizrak (2007), Mercan (2013), Tanrı̈̈ver ve Yamak (2015) ve Doğan ve diğerleri (2016) bulguları ile uyumludur.

Tablo 11: ARDL (3, 2, 1, 0, 1, 0, 0, 3) Model Uzun Dönem Katsayıları

\begin{tabular}{lcccc}
\hline \multicolumn{1}{c}{ Değişkenler } & Katsayı & Std. Hata & t-Statistic & P Değeri \\
\hline BIST100 Endeksi & 0.000214 & 0.000066 & 3.241756 & $0.0015^{*}$ \\
\hline Reel Efektif Döviz Kuru & -0.433791 & 0.073838 & -5.874936 & $0.0000^{*}$ \\
\hline Bütçe Dengesi & 0.000084 & 0.000083 & 1.020390 & 0.3092 \\
\hline Altın Fiyatı & 0.019356 & 0.053762 & 0.360036 & 0.7193 \\
\hline Ham Petrol Fiyatı & 0.008433 & 0.015620 & 0.539888 & 0.5901 \\
\hline İç Borç Stoku & -0.000000 & 0.000000 & -5.714179 & $0.0000^{*}$ \\
\hline Tüketici Fiyatları Endeksi & 0.138781 & 0.047610 & 2.914942 & $0.0041^{*}$ \\
\hline Kukla Değişken & 3993841 & 1.792830 & 2.227674 & $0.0274^{*}$ \\
\hline Sabit Terim & 94.069954 & 9.339088 & 10.072713 & $0.0000^{*}$ \\
\hline
\end{tabular}

Bağımlı Değişken: TRLIBOR

a. “ “*”' ve “**', $1 \%$ ve $5 \%$ düzeyinde istatistiki anlamlılı̆̆ göstermektedir.. 


\section{Sonuç}

Faiz oranları bir ekonominin tüm kanallarını etkilemektedir. Faiz oranlarındaki değişiklikler hem ekonomiyi hem de finansal piyasaları olumlu ve olumsuz etkilemektedir. Enflasyon ve faiz oranları makroekonomik faktörler olarak birbirleriyle ilişkilidir ve diğer faktörleri etkilemektedir. Enflasyon ve faiz oranı arasındaki ilişki üzerinde çok sayıda araştırma bulunmaktadır. Bununla birlikte, faiz oranları ve diğer makroekonomik değişkenleri birlikte inceleyen nadir çalışmalar bulunmaktadır. Bu çalışma, makroekonomik faktörler ile TRLIBOR oranı arasındaki ilişkiyi ele almaktadır. Bu konu çok incelenmediğinden, bu çalışmanın literatüre katkısı olacağı düşünülmektedir. Bu çalışma yatırımcının kararlarına da katkıda bulunacaktır. Yatırımcılar bu değişkenleri öncü gösterge olarak kullanabilirler.

ARDL Modeli değişkenler arasındaki eşbütünleşmeyi gösteren kanıtları sunmaktadır. Reel Efektif Döviz Kuru ve Tüketici Fiyatları Endeksi kısa dönemde \% 1 düzeyinde anlamlıdır. Ayrıca, Reel Efektif Döviz Kuru ve Tüketici Fiyatları Endeksi TRLIBOR'u kısa dönemde gibi uzun dönemde de etkilemektedir. Faiz oranlarınının tahmininde Reel Efektif Döviz Kuru ve Tüketici Fiyatları Endeksi'ni takip etmekte yarar bulunmaktadır. Bu çalışma, enflasyon, kur ve faiz oranları arasındaki ilişkiyi inceleyen Berument ve Malatyalı (2001), Booth ve Ciner (2001), Sever ve Mizrak (2007), Mercan (2013), Tanriöver ve Yamak (2015) ve Doğan ve diğerleri (2016) ile uyumludur.

Bu çalışmada politika faizi, mevduat ve kredi faizlerinde olduğu gibi TRLIBOR ile Reel Efektif Döviz Kuru ve Tüketici Fiyatları Endeksi arsında ilişki bulunmuştur. Faiz ve enflasyon arasındaki ilişki TRLIBOR içinde belirlenmiştir. Yapılan çalışmalarda TCMB politika faizi ve enflasyon arasında karşılıklı olarak aynı yönde bir ilişki olduğu görülmektedir. Bu çalışma TRLIBOR oranında aynı şekilde hareket ettiğini göstermektedir.

Bu çalışma yedi değişken ve 2003:01 ve 2017:06 dönemini kapsamaktadır. Çalışmada daha uzun bir dönem ve diğer makroekonomik değişkenlerin de kullanılmasının faydalı olacağı düşünülmektedir. Ayrıca ABD (FED) ve Avrupa Merkez Bankasının (ECB) 2018 ve 2019 yılı para politikalarının TRLIBOR üzerinde önemli sonuçlar yaratabileceği düşünülmektedir. Bu itibarla FED ve ECB tarafindan alınan kararlar sonrasında TRLIBOR'u etkileyen faktörlerin gelişimlerinin incelenmesi de faydalı olacaktır. 


\section{Kaynakça}

Amaefula, C.G. (2016). Long-run relationship between interest rate and inflation: Evidence from Nigeria, Journal of Economics and Finance, 7(3): 24-28

Apergis, N., \& Eleftheriou, S. (2002). Interest rates, inflation, and stock prices: The case of the Athens Stock Exchange, Journal of Policy Modeling, 24(3): 231-236

Asari, F. F. A. H., Baharuddin, N. S., Jusoh, N., Mohamad, Z., Shamsudin, N., \& Jusoff, K. (2011). A Vector Error Correction Model (VECM) approach in explaining the relationship between interest rate and inflation towards exchange rate volatility in Malaysia, World Applied Sciences Journal, 12(3): 49-56

Berument, H., \& Malatyali, K. (2001). Determinants of interest rates in Turkey, Russian \& East European Finance and Trade, 37(1): 5-16

Booth, G. G., \& Ciner, C. (2001). The relationship between nominal interest rates and inflation: International evidence, Journal of Multinational Financial Management, 11(3): 269-280

Brown, R. L., Durbin, J., \& Evans, J. M. (1975). Techniques for testing the constancy of regression relationships over time, Journal of the Royal Statistical Society Series B (Methodological), 149-192

Cologni, A., \& Manera, M. (2008). Oil prices, inflation and interest rates in a structural cointegrated VAR Model for the G-7 Countries, Energy Economics, 30(3): 856-888

Doğan, B., Eroğlu, Ö., \& Değer, O. (2016). The causal relationship between inflation and interest rates: The case of Turkey, Çankırı Karatekin University Journal of the Faculty of Economics and Administrative Sciences, 6(1): 405-425

Edison, H. J., \& Pauls, B. D. (1993). A re-assessment of the relationship between real exchange rates and real interest rates: 1974-1990, Journal of Monetary Economics, 31(2): 165-187

Engle, R. F., \& Granger, C. W. (1987). Co-integration and error correction: Representation, estimation, and testing, Econometrica: Journal of the Econometric Society, 251-276

Granger, C. W. (1969). Investigating Causal relations by econometric models and cross-spectral methods, Econometrica: Journal of the Econometric Society, 37(3): 424-438

Hashemzadeh, N., \& Taylor, P. (1988). Stock prices, money supply, and interest rates: The question of causality, Applied Economics, 20(12): 1603-1611 
Johansen, S. (1988). Statistical analysis of cointegration vectors, Journal of Economic Dynamics and Control, 12(2-3): 231-254

Johansen, S., \& Juselius, K. (1990). Maximum likelihood estimation and inference on cointegration - with applications to the demand for money, Oxford Bulletin of Economics and Statistics, 52(2): 169-210

Kalulumia, P. (2002). Effects of government debt on interest rates: Evidence from causality tests in Johansen-Type Models, Working Papers, Cahiers De Recherche.

Karaca, O. (2005). Türkiye'de faiz oranı ile döviz kuru arasındaki ilişki: Faizlerin düşürülmesi kurları yükseltir mi?, Discussion Paper, Turkish Economic Association.

Laubach, T. (2007). New evidence on the interest rate effects of budget deficits and debt, Working Paper, Board of Governors of the Federal Reserve System.

Lee, B. S. (1992). Causal relations among stock returns, interest rates, real activity, and inflation, The Journal of Finance, 47(4): 1591-1603

Mahdi, S., \& Masood, S. (2011). The long run relationship between interest rates and inflation in Iran: Revisiting Fisher's Hypothesis, Journal of Economics and International Finance, 3(14): 705-712

Mercan, M. (2013). Enflasyon ve nominal faiz oranları arasındaki uzun dönem ilişkinin Fisher Hipotezi çerçevesinde test edilmesi: Türkiye Örneği, Atatürk Üniversitesi İktisadi ve İdari Bilimler Dergisi, 4(27): 368-384

Mok, H. M. (1993). Causality of interest rate, exchange rate and stock prices at stock market open and close in Hong Kong, Asia Pacific Journal of Management, 10(2): 123-143

Narayan, P. K., \& Smyth, R. (2006). What determines migration flows from lowincome to high- income countries? An empirical investigation of Fiji-Us Migration 1972-2001, Contemporary Economic Policy, 24(2): 332-342

Pesaran, M. H., \& Pesaran, B. (1997). Working with Microfit 4.0: Interactive econometric analysis; [Windows version]. Oxford University Press.

Pesaran, M. H., \& Shin, Y. (1998). An Autoregressive Distributed-Lag Modelling approach to cointegration analysis, Econometric Society Monographs, 31: $371-413$

Pesaran, M. H., Shin, Y., \& Smith, R. J. (2001). Bounds Testing approaches to the analysis of level relationships, Journal of Applied Econometrics, 16(3): 289326

Phillips, P. C., \& Perron, P. (1988). Testing for a unit root in time series regression, Biometrika, 75(2): 335-346 
Sever, E., \& Mizrak, Z. (2007). Döviz kuru, enflasyon ve faiz oranı arasındaki ilişkiler: Türkiye Uygulaması, Sosyal Ekonomik Araştırmalar Dergisi, 1(13): 264-283

Tanrı̈ver, B., \& Yamak, N. (2015). Nominal faiz oranı-genel fiyat düzeyi ilişkisinin Gibson Paradoksu çerçevesinde analizi, Maliye Dergisi, 168: 186-200

Turan, G., \& Curri, V. (2014). Is there any Fisherian link between nominal interest rate and inflation in Albania?, Mediterranean Journal of Social Sciences, 5(13): 334-341

Wang, Y. S., \& Chueh, Y. L. (2013). Dynamic transmission effects between the interest rate, the US Dollar, and gold and crude oil prices, Economic Modelling, 30: 792-798. 


\section{Macroeconomic Factors Influencing Turkish Lira Reference Interest Rate (TRLIBOR)}

\section{Extended Abstract}

\section{Introduction}

Interest rates have an important function in an economy. Changes in interest rate can affect both positively and negatively an economy and financial markets. Interest rates also affect the fund channels. TRLIBOR is the abbreviation of the reference interest rate determined as the Turkish Lira Interbank Offer Rate and TRLIBOR is the equivalent of LIBOR. TRLIBOR is a base reference interest rate among banks or in transactions between banks and customers. Since 2002, it has been announced on daily, weekly, monthly, 2-month, 3-month, 6-month, 9-month and 12month periods in 8 different maturities. TRLIBOR is the lending rate. The borrowing interest rate is TRLIBID. In the period January 2003 - June 2017, the Turkish Lira Interbank Reference Rate decreased from $46.0 \%$ to $12.38 \%$.

There are many studies on interest rate in the financial literature. In these studies, the relationship between interest rates and inflation, stock prices, exchange rate and debt stock is examined. Several studies have examined the relationship between interest rate and macroeconomic factors. The aim of this study is to determine macroeconomic factors affecting interest rate.

\section{Method}

This study covers seven variables and the period between 2003:M01 and 2017:M06. ARDL Model indicates the evidence of cointegration between variables. PP Unit Root Test results and Augmented Dickey-Fuller (ADF) unit root test results show that the variables are stable at 1 difference level. FPE and AIC take the lowest initial critical value in the third stage. Therefore, it is clear that there is no autocorrelation during the third delay period. In addition to autocorrelation, White Test has investigated the variability of variance and there is no variance in the model.

There is a structural break in the model. The effects of the crisis are evident in times of global crisis. Therefore, for the period of 2010: M03-2011: M02 a dummy variable should be added. After adding dummy variables to the model, CUSUM and CUSUM SQ Tests were performed. According to CUSUM and CUSUM SQ test results, there is no structural break in dummy variable model.

\section{Results and Discussions}

ARDL Model can be created to determine long and short term coefficients. Engle and Granger (1987), Johansen (1988) and Johansen and Juselius (1990) Cointegration Tests are generally used to test cointegration and to examine the long-term relationship between variables. These tests can be applied when all series have unit roots and are stationary at the first difference level. If the series has different levels of stability, it is not possible to perform these tests. However, the Autoregressive Distributed Lag-ARDL approach (2001), developed by Pesaran and Pesaran (1997), Pesaran and Shin (1998) and Pesaran et al. do not count whether the variables of the model in the ARDL test are stationary at the original level or at the first difference level. The advantage of this test is that it allows for cointegration analysis between variables of different stationary level.

The ARDL approach consists of a 3-step process. In the first step, the ARDL Boundary Test examines the existence of a long-term relationship between variables. The second and third steps 
conditionally examine a long-term relationship between variables. Therefore, long-term and shortterm coefficients can be reached respectively (Narayan and Smyth, 2006: 337).

The variables in the model are cointegration. According to the cointegration coefficient, short and long term imbalances will be corrected by approximately $18 \%$ at the end of a period. In addition, the Real Effective Exchange Rate and Consumer Price Index is statistically significant at $1 \%$ in the short term. A one-point change in the Real Effective Exchange Rate adversely affects TRLIBOR by $14 \%$ and a one-point change in the Consumer Price Index affects TRLIBOR positively by $13 \%$. In addition to the Consumer Price Index and the Real Effective Exchange Rate, the Gold Price has an impact on TRLIBOR in the short term and a one-point increase in the Gold Price causes a decrease of $5 \%$ in TRLIBOR.

According to the long-term coefficients; BIST100 Index, Domestic Debt Stock, Real Effective Exchange Rate and Consumer Price Index are statistically significant at $1 \%$ level in long term. Although domestic debt stock is statistically significant, its coefficient is almost zero. Furthermore, there is a weak relationship between TRLIBOR and BIST100 Index. On the other hand, the Real Effective Exchange Rate and Consumer Price Index affects TRLIBOR in the long run as well as the short-run. The results of this study are consistent with the findings of Berument and Malatyalı (2001), Booth and Ciner (2001), Sever and Mizrak (2007), Mercan (2013), Tanriöver and Yamak (2015) and Doğan and others (2016).

Real Effective Exchange Rate and Consumption Price Index are significant in the short and long term. According to the Granger causality test results, there is one way causality from TRLIBOR to the Real Effective Exchange Rate and the Consumer Price Index. According to the results of the Variance Decomposition Test; a significant part of the error variance in TRLIBOR is explained by itself, real effective exchange rate is $1.21 \%$ and the Consumer Price Index is $4,90 \%$.

\section{Conclusion}

The ARDL Model provides evidence of cointegration between variables. The Real Effective Exchange Rate and Consumer Price Index is significant at $1 \%$ in the short term. In addition, the Real Effective Exchange Rate and Consumer Price Index affects TRLIBOR in the long run as well as in the short term. It is useful to follow the Real Effective Exchange Rate and Consumer Price Index in estimating interest rates.

In this study, the relation between TRLIBOR and Real Effective Exchange Rate and Consumer Price Index has been observed as in policy rate, deposit and loan rates. The relationship between interest and inflation is determined in TRLIBOR. In the studies conducted, it is seen that there is a mutual relationship between the policy rate and inflation. This study shows that the TRLIBOR ratio is the same.

This study covers seven variables and 2003: 01 and 2017: 06 periods. It is thought that it will be useful to use longer term and other macroeconomic variables in the study. Moreover, the monetary policies of the US (FED) and the European Central Bank (ECB) for 2018 and 2019 are expected to have significant consequences on TRLIBOR. Therefore, it would be useful to examine the development of factors affecting TRLIBOR after decisions taken by FED and ECB. 